\title{
Optimizing Border-Post Cargo Clearance with Auto-ID Systems
}

\author{
Ernest Bhero and Alwyn Hoffman
}

The Discipline of Electrical, Electronic and Computer Engineering, School of Engineering, University of KwaZulu Natal, Durban, South Africa,

bhero@ukzn.ac.za

The School of Electrical, Electronic and Computer Engineering, Faculty of Engineering, Northwest University, Potchefstroom, South Africa

alwyn.hoffman@nwu.ac.za

\section{Received 24 August 2013; Accepted 18 December 2013}

Publication 23 January 2014

\begin{abstract}
Stakeholders in cross-border logistics and trade corridors have always been concerned about ways of improving operational efficiency. Cargo owners and cargo forwarders have been particularly concerned with long delays in the processing and clearing of cargo at border-posts. It is reasonably suspected that the delays are due to a combination of a lack of optimum systems' configurations and the inefficient human-dependent operations, which makes the operations prone to corruption. This paper presents the findings of a study, which is being conducted to determine the sources of the inefficiencies and then suggest possible solution based, largely, on RFID technology. The procedure and preliminary findings are presented.
\end{abstract}

Keywords: Road Freight Transport, Cross-border, Customs Processes, GPS Tracking, RFID, OSBP, Choke Monitoring.

\section{Introduction}

Over the years, there has been a steady increase in levels of international freight movement, thanks to globalization. Although the bulk of the freight is ocean

Journal of Machine to Machine Communications, Vol. 1, 17-30.

doi: 10.13052/jmmc2246-137X.111

(c) 2014 River Publishers. All rights reserved. 
bound, road transport remains an important link in multi-modal freight supply chains [11]. On the African continent this dependence on road transport is even more prominent due to the absence or bad state of railway lines. In Africa, many countries are landlocked, which means a significant portion of road freight must travel along multinational corridors [11]. While many economic regions are gradually doing away with the charging of customs duties at border posts [12], the opposite is true in Africa, where the majority of countries are still dependent on customs duties as their primary source of state income [7]. Stringent controls are, therefore, applied at most border posts to ensure that freight does not leak into or from a country before the required duties are paid.

The effective management of road transport is complicated by the involvement of a wide spectrum of independent stakeholders. The cross-border movement of a freight consignment includes at least the cargo owner (or consignor), the transport company, potentially a transport broker, a freight forwarder, a clearing agent, roads agencies, customs authorities on each side of the border, and a customer (or consignee). While the commercial players have objectives that are well aligned and aimed at operational efficiencies, the agencies responsible for protecting roads infrastructure and collecting customs duties are more concerned about the effectiveness of control measures aimed at the prevention of illegal practices.

Current cross-border freight management systems are characterized by a lack of transparency from the perspective of the consignor and consignee and by little coordination between the actions of different role-players. The lack of visibility of operations at ground level results in long average delays at border posts accompanied by many corrupt practices - often these two go hand in hand $[1,8]$. While lacking integration between the systems operated by different stakeholders is partly to blame, deliberate manipulation of the process by human operators (who know that their actions are difficult to police) also plays a major role.

This paper will focus on cross-border operations of typical border-posts in sub-Sahara Africa. Firstly, the paper analyzes practical studies performed at typical border-posts to measure the average delays experienced by freight consignments $[9,10]$.

Secondly, the paper proposes an improved cross-border management concept, based on the use of information and communication technologies and on the integration between the systems operated by private and public sector stakeholders. 
Thirdly, the paper presents possible improvements on border-posts operations based on related studies.

\section{Literature Review}

In this section, we will consider, firstly, the empirical work done to evaluate the current state of affairs at selected border-posts and the related theoretical studies of possible improved scenarios.

\subsection{Border-Post Operations Field-Studies}

Extensive work has been done to determine work flows at border-posts and to determine the major contributing factors for the undue delays experienced at border-posts [11]. In this presentation, we will focus on the Chirundu border-post because Chirundu is now a One Stop Border-Post (OSBP). OSBPs have been suggested as alternative configurations to traditional border-posts; the rationale for OSBP was that it would improve operational efficiencies of border-posts. Table 1 summarizes the field-work done at Chirundu border-post, $[9,10]$.

The table shows time-delays for various border activities before and after the border was turned into an OSBP. The summary of the field work indicates that:

- Customs, Document Processing and Agent times have actually doubled.

- Driver Idle Time has increased by about $27 \%$.

- Not apparent from Table 1, 50\% of all vehicles crossed the border within 24 hours.

Table 1

\begin{tabular}{lcc}
\hline \multicolumn{3}{c}{ TMSA Choke Monitoring at Chirundu } \\
\hline Comparative Category & Current & Comparative \\
& OSBP & Pre-OSBP \\
& Data & Data \\
\multicolumn{1}{c}{ Summary of Bottlenecks in Hours - North bound } & \\
Agent & $12: 31$ & $6: 00$ \\
Customs & $45: 27$ & $21: 00$ \\
Driver Idle Time & $14: 06$ & $11: 00$ \\
Immigration & $0: 31$ & 0.00 \\
Document Processing & $57: 58$ & $27: 00$ \\
Inspection Time & $1: 14$ & $1: 00$ \\
\hline
\end{tabular}


These observations among others indicate that the objective of establishing an OSBP was not entirely achieved; in fact the objective seems to have been completely eroded and reversed. However, the fact that $50 \%$ of the vehicles crossed the border within 24 hours comes as consolation.

The report of the work, $[9,10]$, confirmed the conviction that, the apparent failure of this OSBP is due mainly to negative human conduct. This observation further strengthens the belief that, the possible solution lies in automating most of the operations and closely monitoring human conduct in a way that fosters accountability.

\subsection{Trade Facilitation Objectives of Sub-Sahara Regional Bodies}

In a COMESA-SADC meeting held in Gaborone, Botswana on the $3^{\text {rd }}$ and $4^{\text {th }}$ of February 2011, the objectives of the Regional Economic Communities (REC) as far as trade facilitation was clearly spelt-out, [14]. The mission objectives read:

"The main objective of the meeting was to finalize and adopt a Joint Strategy and Work Plan for the development and implementation of a joint SADCCOMESA CUSTOMS Transit Management Information System and to discuss and possibly come up with a road map on the simplification and harmonization of a Transit Management System in the regions."

The findings and the report of that meeting indicated that, there is political will not only at Governmental levels but at regional levels too to facilitate harmonious trade between member countries. The meeting also brought out the imperative nature of the need to optimize trade processes in the region. From the report, it is apparent that, the RECs aim, mostly, at harmonizing information interchange at customs level and not at improving operational efficiencies at other levels such cross-border operations. Thus, there is need to compliment the REC's effort in this regard.

\subsection{Related Studies on Trade Corridors' Operations Optimization}

The most notable study in a related area was done by Hsu et al [2]. This study looked at import cargo processing in an air cargo terminal. It then constructed a customs clearance-network based on cargo, information and human flows. The flow network lead to the sub-division of the network into several operational units and a customs clearing team would work on separate units. 
The study then formulated a mathematical model for describing the customs clearance process delay and how it affects the delay of cargo arriving later. The performance at the cargo terminal was then assessed and analyzed on the basis of this model. RFID system was then introduced in relevant operational units such as replacing some labour operations, identification function and position locating functions. The decrease in cargo owner's inventory cost and terminal operators' labour cost were evaluated to measure the gains of reducing delays due to the use of RFID system at the air cargo terminal. The analysis, indicated performance of about $63 \%$. However, the researchers indicated a decrease in percentage when the volume of cargo handled per given time increased beyond a certain limit. This decrease in performance is attributed to the limit in the number of work teams working on customs clearance.

Although this work, [2], was carried out at an air cargo terminal, it bears close resemblance with cross-border operations. We will present a detailed comparison in the subsequent sections and try and draw insight into cross-border operations.

\section{Analysis of Border Post Operations}

In this section, we will analyse the typical process flow diagram at a border-post, analyse the typical border-post layout and then identify possible process flow bottle necks.

\subsection{Typical OSBP Border Post Process Flow Diagram}

Figure 1 below shows the process flow diagram for OSBP (for example, Chirundu).

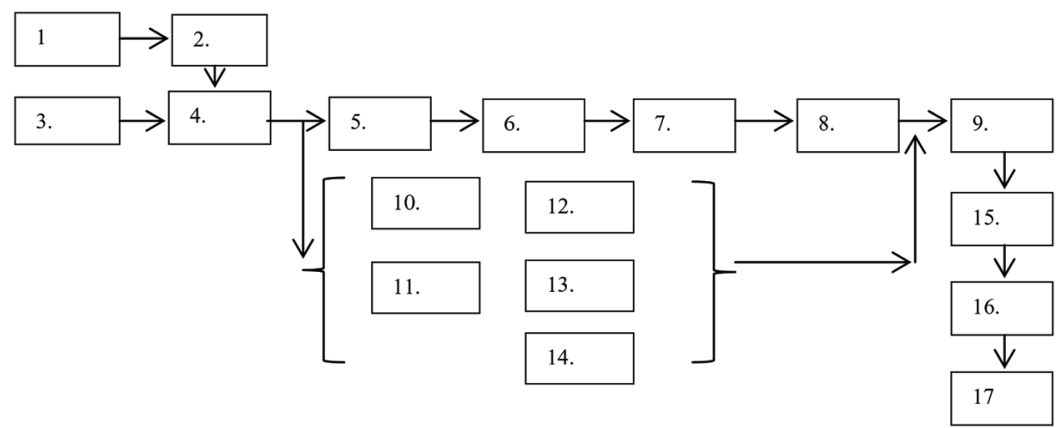

Figure 1 Typical Border-post Work Flow 
Table 2

1. Lodging of manifest for preclearance.

2. Pre-clearance and pre-payment.

3. Travel from origin to border post.

4. Consignment arrives at border post.

5. Driver submits documents to agent.

6. Agent prepares documents for submission to customs.

7. Agent submits documents to customs.
8. Customs process clearance.

9. Payment of customs duties and other payments.

10. Driver goes through immigration procedures.

11. Vehicle weighed at weigh-bridge.

12. Vehicle scanned at scanning shed.

13. Physical inspection of consignment.

14. Inspections by other border agencies.
15. Customs release consignment (docs to agent).

16. Agent hands documents to driver.

17. Consignment leaves the border / cross to other side.

The activities in the flow chart are summarized in Table 2, [10]:

From Table 1 we note that, activities 6, 7, 8,9 and 15 contribute immensely to the delays observed at the border-posts. As mentioned earlier, the delays observed at the border-posts are due to a combination of factors; human and system configurations. Thus, the solution sort is multifaceted; finding and suggesting improved system configurations and minimizing human involvement and closely monitoring human activities by use of auto-ID systems lead by RFID.

\subsection{Typical Border Post Layout}

Figure 2 below shows typical border-post layout.

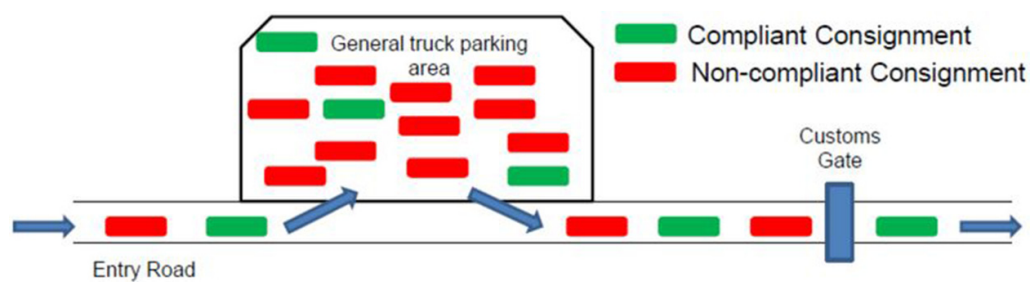

Figure 2 Typical Current Border Post Lay-out 
In this layout, compliant consignment and non-compliant consignment queue into and out of the border using a single lane. There is parking yard for both consignments. In this configuration, it often happens that, a compliant consignment is blocked by a non-compliant truck (consignment). The end result is that, the compliant consignment gets unduly delayed just like the noncompliant consignment. At the end of the day, the benefits for being compliant are diminished and therefore would save no purpose in being compliant.

\section{Proposed Solution and Simulated Results}

We begin this section by presenting a proposal for border-post layout re-configuration and why that change is presumed beneficial. We then propose an RFID-based system to automate certain border-post operations with a presumed improvement in operational efficiency at border-posts. We conclude this section by presenting a comparative study of border-post operations as compared to the work of Hsu et al [2] and thereby presenting the simulated results.

\subsection{Proposed Layout Re-configuration}

Figure 3 shows a modified border-post layout. The rationale for this layout is that, compliant consignment should not be unduly delayed. On entering the customs/immigration yard, the road is split into two, the "green lane" for compliant cargo and "red lane" for non-compliant or suspicious cargo. At the entry gate, there will be RFID readers, which automatically read tags from entering trucks and determine the risk status of the cargo (whether compliant or not). The Auto-ID system will then open appropriate boom gate into the green lane or the red lane. Thus, the compliant cargo will move freely and fast through the customs/immigration area. The non-compliant cargo will have to

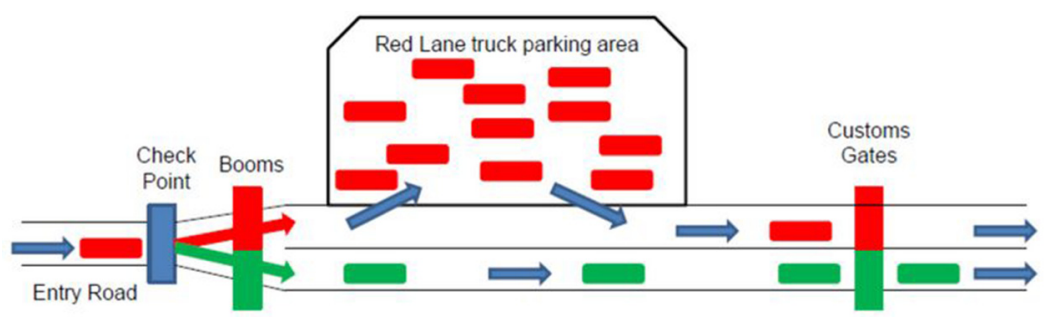

Figure 3 Green Lane /Red Lane Border Post Layout 
go to the parking yard for inspection. It should be noted that, green lane layout will work better with pre-clearing and pre-payment as indicated in Figure 1 above. What else can be done to further enhance the green lane concept?

\subsection{Proposed Pro-RFID System Assisted Operations}

\subsubsection{RFID technology}

RFID means Radio Frequency Identification. It is an emerging and independent interdisciplinary field. It combines technologies such as HF technology and EMC, data protection and cryptography, semiconductor technology, telecommunications and other related areas. RFID is widely used, if not exclusively used, in automatic identification procedures. The Auto-ID procedures can provide information about people, animals, goods and products in transit. RFID system comprises of RFID readers and a variety of transponders or tags. The tags can either be passive or active tags. Tags are also categorized in terms of their frequency of operation. The RFID readers establish a link between back-end system (databases and networks) and the front-end system, which is made up of tags and other related auto-id procedures. The RFID reader wirelessly communicate and extract information/data from tags and relay this information for processing in the back-end system or in a standalone system, the reader can process the data/information and carryout required tasks.

\subsubsection{The proposed RFID-based system}

Auto-identification systems have existed since the 1960s when the barcode system was first introduced. Today we have a wide range of autoidentification systems in the market and RFID has been growing fast as an auto-identification system of choice in wide-ranging applications. But, according to, [15], technology adoption is not always about choosing the dominant design but about how to future-proof an auto-ID implementation. Thus, although the researchers suggest a predominantly RFID based auto-id system in this work, the researchers are mindful of the need to incorporate other auto-id systems and indeed that arm of work is being researched on too.

From our analysis of Table 1 and Figure 1, it is apparent that the customs processes, document processing, which is done by the customs officials and the Agents contribute the longest delays. Thus, we propose the use of electronic documents or to have documents that are embedded with an RFID tag. The tag will contain information like what is normally found on the manifest document and declaration or consignment data. This allows Electronic Data Interchange (EDI) between the cargo owners or their Agents and the customs authorities. 
Further, the cargo itself will be tagged and this allows the RFID readers at the entrance to read the tags and identify the cargo as it arrives. The cargo identity is then feed to the control centre, which then initiates immediate processing of the consignment. The risk engines of the customs will then determine the risk level of the consignment and alert the inspection team whether to physically inspect a particular cargo or not. All the information interchange is done electronically thereby improving the rate of document processing. The human labour removed from document processing can be deployed in the inspection bays and monitoring the entrance and exit points. Implementing the system as just described will substantially remove human involvement in the document processing and this is expected to improve the performance at the border-posts.

\subsubsection{Comparative study with the research work in [2]}

Performance of envisaged system was assessed solely on the basis of closely related work such as [2]. The related work in [2] was done at an air terminal (airport) in Taiwan; yet in this study it is the border-posts which are the main focus. The following subsections discuss the differences and similarities between the two studies. The comparisons enable us to predict the possible performance improvement for the border-posts.

- Differences:

i. Air terminals handle mostly high value and perishable goods.

ii. At air terminals, cargo is removed from the aeroplane and temporarily stored by customs during processing and inspection.

iii. At air terminals, there are no trucks carrying cargo.

iv. Air terminals handle less cargo per given time compared to border-posts.

\section{- Similarities:}

i. In both systems we have; information flow, human flow and cargo flow paths.

ii. Both systems have document processing by customs and/or Agents or customs brokers.

- Simulated Results:

In the analysis by Hsu et al [2], the following equation was formulated to describe time taken by $\mathrm{c}^{\text {th }}$ cargo to go through various clearance processes. 
$t_{u, r}^{c}=\operatorname{Max}\left\{A_{u, r}^{c-1}+t_{u, r}^{c-1}-A_{u, r}^{c}-S_{c-1, c}, 0\right\}+I_{u, r}^{c} \quad \forall u, r, c$

Where:

$-t_{u, r}^{c}$ is the total time taken by $\mathrm{c}^{\text {th }}$ cargo to complete activities of operation at stage $\mathrm{u}$ handled by working team $\mathrm{r}$.

$-I_{u, r}^{c}$ is the cargo handling and waiting time.

- $A_{u, r}^{c}$ is the accumulative time taken by cargo for completing all upstream activities at parts 1 to u- 1 . Note, $A_{1, r}^{c}=0$.

- $S_{c-1, c}$ is the time headway between (c-1) ${ }^{\text {th }}$ and $\mathrm{c}^{\text {th }}$ cargos.

According to the study, [2], the cargo at the Taiwan air cargo terminal goes through a total of six stages of clearing operations. With reference to Figure 1, we see that there is a possible maximum of four stages of clearing operations; if the 'other inspections' (block diagram 14) and weighing (block diagram 11) are assumed to be negligible there will only be two stages. Thus, for compliant cargo, the delay bull-whip effect will be minimal for borderposts compared to air terminals. Using time delays in Table 1 together with process flow diagram in Figure 1, we have Figure 4, which shows the possible resultant improvement on processing time when an auto-id system lead by RFID is implemented.

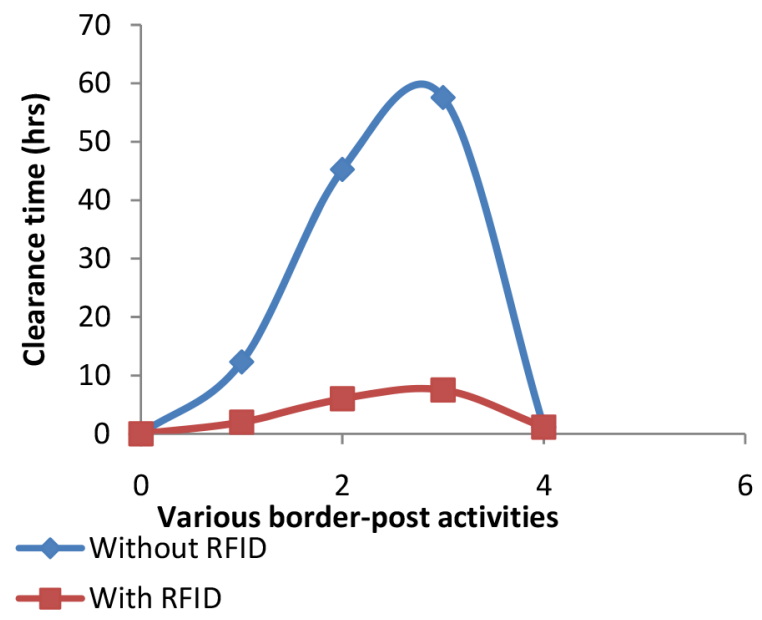

Figure 4 Processing time 


\section{Discussions and Conclusions}

The expected performance improvement depicted in Figure 4 has assumed an ideal auto-id system. It has also assumed no negative human interference. In reality individuals can delay capturing or scanning documents. Therefore, there is need to bring a system with a human activity monitoring functionality to the proposed system. Also, the system will be more complete if it can monitor movement of cargo throughout the transit period of cargo from source to destination. If the tracking data is shared or linked to customs' cargo risk engines, then it becomes easier to separate compliant from non-compliant cargo. This would further enhance the usefulness of the system with the overall expected improvement in trade facilitation. However, a more detailed modelling of every stage is required in order to come up with a system close to realistic settings. Further work being done include; investigating impact of current ICT paradigms on the implementation of the envisaged system and what levels integration of various systems used by different stakeholders is realistically possible.

\section{References}

[1] http://ieg.worldbankgroup.org/content/dam/ieg/gac/gac_eval.pdf World Bank Country-Level Engagement on Governance and Anticorruption. Accessed $9^{\text {th }}$ of April (2013).

[2] C. I. Hsu, H. H. Shih and W. C. Wang, "Applying RFID to reduce delay in import cargo customs clearance process". Computers \& Industrial Engineering Volume 57, (2009).

[3] J. Siror, S. Huanye, W. Dong and W. Jie, "Application of RFID technology to curb diversion of transit goods in Kenya". Fifth International Conference on INC, IMS and IDC (2009).

[4] J. Siror, S. Huanye and W. Dong, "Evaluation of RFID Based Tracking Systems for Securing Transit Goods in East Africa". Sixth International Conference on Digital Content, Multimedia Technology and its Applications (2010).

[5] J. Siror, S. Huanye, W. Dong, L. Guangun and P. Kaifang, "Impact of RFID technology on tracking of export goods in Kenya". Journal of convergence information technology Volume $\mathbf{5}$ number nine. (2010). 
[6] B. Li and W. F. Li, 2010, "Modeling and Simulation of Container Terminal Logistics Systems Using Harvard Architecture and Agent-Based Computing". Proceedings of the 2010 Winter Simulation Conference.

[7] A. J. Hoffman, "The use of technology for trade corridor management in Africa", NEPAD Transport Summit, Sandton, South Africa, October (2010).

[8] "Bribery as a non-tariff barrier to trade - a case study of East Africa trade corridors", Transparency International-Kenya (2012).

[9] M. Fitzmaurice, "Optimization plan for freight movements at key commercial border crossings", Report compiled by Transport Logistics Consultants, August (2009).

[10] M. Fitzmaurice, "TLC Report on Beitbridge, Chirundu, Kasumbalesa and Nakonde", November (2012).

[11] S. Mpata, "Evaluation of the COMESA/SADC transit management systems - Final Report", Lilongwe, Malawi, September (2011).

[12] L. Norov and D. Akbarov, "Customs - time for a change", Problems of Economic Transition, vol. 52, no. 2, pp. 47-60, June (2009).

[13] http://www.afdb.org/fileadmin/uploads/afdb/Documents/Knowledge/20 09\%20AEC-\%20Towards\%20an\%20EAC $\% 20$ COMESA $\% 20$ and $\% 20 \mathrm{~S}$ ADC\%20Free\%20Trade\%20Area\%20Issues\%20and\%20Challenges.pd f Evaluation of the COMESA/SADC Transit Management Systems: September, 2011. Accessed 21/04/2013.

[14] http://www.trademarksa.org/sites/default/files/publications/Mission\%20 Report\%20\%7C\%20COMESA-ADC\%20Cooperation\%20on\%20Custo $\mathrm{ms} \% 20$ Transit\%20Management\%20Information\%20System $\% 20 \% 7 \mathrm{C} \%$ 20February\%202011.pdf Mission Report on COMESA-SADC Cooperation on Customs Transit Management Information System. Accessed 21/04/2013.

[15] http://ieeexplore.ieee.org/stamp/stamp.jsp?tp=\&arnumber=4037179 The Hybridization of Automatic Identification. Accessed 02-01-2012

[16] S. R. Hong, S. T. Kim, C. O. Kim, "Neural network controller with on-line inventory feedback data in RFID-enabled supply chain", International Journal of Production Research, volume 48, November (2009).

[17] A. Ustundag, "Evaluating RFID investment on a supply chain using tagging cost sharing factor", International Journal of Production Research, volume 48. November (2009). 
[18] S. J. Wang, C. T. Huang, W. L. Wang, Y. H. Chen, "Incorporating ARIMA forecasting and service-level based replacement in RFID-enabled supply chain", International Journal of Production Research, volume 48, November (2009).

[19] N. Langer, C. Forman, S. Kekre, A. Scheller-Wof, "Assessing the Impact of RFID on Return Centre Logistics", Interfaces Vol-37, December (2007).

\section{Biographies}

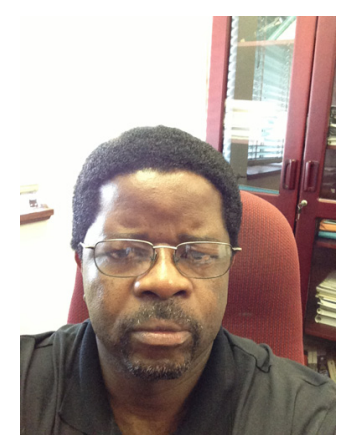

Ernest Bhero is a lecturer in the Discipline of Electrical and Electronic Engineering at the University of KwaZulu Natal, Durban, South Africa. He holds B. Eng. (Electronics), MPhil (Electronics) and a PhD candidate with North-West University. As an Engineer, he designed and developed three electronic products that were commercialised in Zimbabwe. The areas of interest and research include; Computer Architecture and Organization, Embedded Systems and RFID Systems and their application in improving efficiency in trade corridors' operations. 


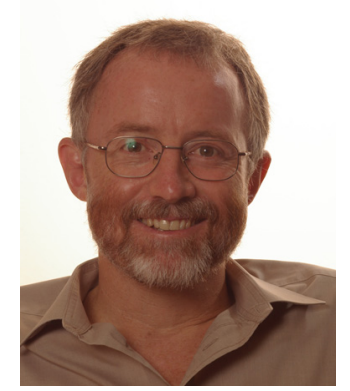

Alwyn Hoffman was born in Bloemfontein, South Africa in 1962. He received the B. Eng. (Electronics) degree in 1985, the M. Eng. (Electronics) in 1987, the $\mathrm{Ph}$. D. (Electronics) in 1991 and the MBA degree in 1996, all from the University of Pretoria. After working in the South African high technology electronics industry during the period 1985 to 1994, he joined Northwest University in October 1994 as Director of the School of Electrical and Electronic Engineering for a period of 6 years. Between 2001 and 2008 he again spent time in the high-technology industry, working for Inala Technology Investments during 2001 in the field of intellectual property development and for IPICO Inc., a company listed on the Toronto Stock Exchange, during the period 2002 till 2008 in the field of automated identification. In January 2009 he rejoined Northwest University's Faculty of Engineering, and is still involved as consultant in the local and global electronics and communication industries. His research field includes wireless communications and artificial intelligence. 